\title{
Gripe española y dinámicas laborales en la Argentina de principios del siglo XX
}

\author{
Spanish flu and labor dynamics in Argentina at the beginning of the \\ 20th century
}

\section{Adrián Carbonetti ${ }^{*}$ María Dolores Rivero*}

Resumen: Movidos por el suceso epidemiológico actual, el covid-19, y los resquebrajamientos económicos a los que asistimos, en este estudio nos interrogamos por el impacto que supuso la pandemia más cruenta del siglo XX sobre la economía y las condiciones de trabajo en Argentina: la gripe española. Esta aproximación, llevada a cabo mediante una metodología cualitativa anclada en la hermenéutica, se asienta en el estudio de fuentes periodísticas y testimonios médicos de época. A partir de ellos pretendemos mostrar cómo el advenimiento de la dolencia - cristalizado en dos grandes oleadas - sacudió las estructuras económicas y productivas de diferentes regiones del país, generando lógicas laborales particulares.

Palabras clave: gripe española; mercado de trabajo; Argentina.

Abstract: Moved by the current epidemiological event, the covid-19, and the economic breakdowns we are witnessing, in this study we ask ourselves about the impact of the bloodiest pandemic of the 20th century on the economy and working conditions in Argentina: the Spanish flu. This approach, carried out using a qualitative methodology anchored in hermeneutics, is based on the study of journalistic sources and medical testimonies of the time. From them we intend to show how the advent of the disease - crystallized in two great waves - shook the

* Doctor en Demografía por la Facultad de Ciencias Económicas por la Universidad Nacional de Córdoba (UNC). Profesor titular en la Facultad de Ciencias Sociales (UNC). Profesor Contratado de la Facultad de Humanidades y Ciencias, Universidad Nacional del Litoral (UNL). ORCID: https://orcid.org/0000-0002-20932046. E-mail: acarbonetti2012@gmail.com.

** Doctora en Historia por la Facultad de Humanidades y Ciencias de la Educación de Universidad Nacional de La Plata (UNLP). Becaria posdoctoral (CIECS-CONICET y UNC). ORCID: https://orcid.org/0000-0002-00683281. E-mail: doloresriv@gmail.com. 
economic and productive structures of different regions of the country, generating particular labor logics.

Keywords: spanish flu; work market; Argentina.

\section{Introducción}

L

A ACTUAL PANDEMIA de covid-19 viene sacudiendo fuertemente la economía de la mayoría de los países del mundo, incluso - y tal vez con mayor impulso - las de las naciones más pujantes del esquema centro-periferia. A partir de allí viene gestándose toda una serie de elucubraciones acerca del futuro del capitalismo y de interrogantes en torno a la relación capital-trabajo a partir de las tasas de desocupación que se observan en la mayoría de los territorios donde penetró el flagelo.

Una manera de contribuir en el análisis de la problemática de las enfermedades de origen pandémico o epidémico y su relación con el ámbito económico y la fuerza laboral es volviendo la mirada hacia la historia. Concretamente, nos referimos a intentar rastrear algunos indicios - en el marco de hitos epidemiológicos pasados específicos - que nos permitan entender los comportamientos de las economías nacionales y regionales y la forma en que los Estados enfrentaron las configuraciones y contradicciones del mundo del trabajo en medio de una pandemia.

Este tipo de evento ha traído consigo a lo largo de la historia de la humanidad crisis de carácter sanitario, económico, social e incluso político. Claro que estas coyunturas tendrían un cariz particular en ciudades, regiones o países signados por el capitalismo. Esta afirmación se sostiene a partir de observar que numerosas facetas de las pandemias se encontraron interconectadas y modificaron patrones económicos: la muerte, la enfermedad, la huida o el aislamiento de aquellos habitantes que conformaban la fuerza laboral de una población desequilibraron la ecuación entre capital y trabajo.

En el caso argentino, podemos aseverar que esa fuerza laboral debió ser atendida por los más variados organismos e instituciones: el sistema sanitario administrado por el Estado, la Iglesia y hasta las asociaciones de beneficencia. $Y$ es que como es sabido, las dolencias infectocontagiosas que acecharon sistemáticamente a la población rebasaban la salud pública (aun endeble y poco articulada en los albores del siglo XX), hecho que generó crisis políticas. El Estado nacional, los provinciales y municipales mostraban - en términos generales - ineficiencia para mitigar los sucesivos brotes epidémicos y esto despertaba respuestas enconadas.

Numerosos son los estudios que, desde una perspectiva historiográfica y anclados en el binomio salud/enfermedad, retoman múltiples dimensiones de determinadas enfermedades. Sin embargo, una revisión de la producción argentina devela que son exiguos los trabajos 
que colocan en perspectiva analítica las lógicas laborales que jalonan las dolencias o las asociaciones entre unas y otras. Adrián Carbonetti, ${ }^{1}$ Diego Armus $^{2}$ y Héctor Recalde ${ }^{3}$ se han interrogado acerca de las vinculaciones entre algunas actividades y la tuberculosis para los casos de Córdoba y Buenos Aires, respectivamente. Otras aproximaciones han ponderado entramados relativos a los accidentes laborales y a los trabajos que "enferman". ${ }^{4}$ En esta línea, y para el caso tucumano, se destaca el estudio de María Estela Fernández que - si bien tangencialmente - refiere a la salud de los trabajadores de los ingenios azucareros. ${ }^{5}$ En lo que a vicios, "conductas inmorales" y males respecta, Paula Sedrán da cuenta - para la provincia de Santa Fe de mediados del siglo XIX - de las conexiones existentes entre ebriedad y "la peonada", aunque también refiere a soldados, vigilantes y gendarmes. ${ }^{6}$ Para el mismo enclave, pero enfocándose en la ciudad de Rosario, María Luisa Múgica aborda la relación entre la prostitución reglamentada y las enfermedades venéreas. ${ }^{7}$

Este escrito pretende nutrir esta línea aun fértil, a partir de analizar el impacto que supuso la gripe española sobre la economía y las condiciones de trabajo en Argentina a comienzos del siglo XX. Nuestra aproximación, llevada a cabo mediante una metodología cualitativa anclada en la hermenéutica, se asienta en el estudio de fuentes periodísticas, demográficas y testimonios médicos de época. Específicamente, indagamos en la información recogida en los diarios La Nación, La Prensa, Nueva Época y Los Principios. También en aquella que proveen la tesis de José Tobías, los Anales del Departamento Nacional de Higiene y el Instituto Nacional de Estadística y Censos de la República Argentina. A partir de este caudal documental intentaremos mostrar cómo el advenimiento de la dolencia sacudió las estructuras económicas y productivas de diferentes regiones del país, generando lógicas laborales particulares.

1 CARBONETTI, Adrián. La ciudad de la peste blanca. Historia epidemiológica, política y cultural de la Tuberculosis en la ciudad de Córdoba, Argentina. 1895-1947. Puebla: Dirección de Fomento Editorial, Benemérita Universidad Autónoma de Puebla, 2011.

2 ARMUS, Diego. La ciudad impura: salud, tuberculosis y cultura en Buenos Aires, 1870-1950. Buenos Aires: Edhasa, 2007.

3 RECALDE, Héctor. La salud de los trabajadores en Buenos Aires (1870-1910): A través de las fuentes médicas. Tesis (Doctorado en Historia) - Facultad de Humanidades y Ciencias de la Educación, Universidad Nacional de la Plata, La Plata, 1993.

4 RAMACCIOTTI, Karina Inés. De la culpa al seguro. La Ley de Accidentes de Trabajo, Argentina (1915-1955). Mundos do Trabalho, Florianópolis, v. 3, n. 5, p. 266-284, 2011; Idem. Diálogos transnacionales entre los saberes técnicos e institucionales en la legislación sobre accidentes de trabajo, primera mitad del siglo XX. História, Ciências, Saúde-Manguinhos, Rio de Janeiro, v. 22, n. 1, p. 201-21, 2015.

5 FERNÁNDEZ, María Estela. Ocupaciones y oficios en Tucumán en el Marco de las especialización azucarera (1869-1895). Tesis (Maestría en Ciencias Sociales. Mención en Historia) - Universidad Nacional de Tucumán, Tucumán, 2003.

6 SEDRÁN, Paula. Moral y orden. Sentidos y prácticas en la transformación de los comportamientos públicos (Santa Fe, 1856-1890). Buenos Aires: Teseo, 2018.

7 MÚGICA, María Luisa. La ciudad de las Venus impúdicas. Rosario, historia y prostitución, 1874-1932. Rosario: Laborde Editor, 2014; MúGICA, María Luisa. Males vergonzantes y prostitución reglamentada. Rosario, Argentina (1874-1932). Asclepio, v. 68, n. 2, p. 1-18, 2016. 


\section{Los derroteros de la gripe española en Argentina}

DURANTE LOS MESES de mayo y junio de 1918, los periódicos argentinos comenzaron a dar noticias acerca de una enfermedad exótica que estaba haciendo estragos en España. ${ }^{8}$ Los argumentos acerca del contagio se anclaban, fundamentalmente en aspectos nutricionales: el desarrollo de esta dolencia se presentaba como la consecuencia de la pobreza de artículos alimenticios en la dieta española. Por otro lado, la misma comunicación daba cuenta de la extensión del mal hacia varios países de Europa y de lugares alejados entre sí, como Dinamarca y Portugal. ${ }^{9}$ Sin embargo, el periódico no alertaba a los lectores acerca de los riesgos que implicaba para la salud de los habitantes de la Argentina la extensión de la pandemia hacia América del Sur. Es que la prensa nacional de por entonces no se ocupaba de una enfermedad que se arrasaba en los países europeos devastados por el hambre y la guerra; era una realidad lejana no sólo por la distancia intercontinental, sino también por la creencia de que en estas latitudes existía cierto grado de inmunidad como consecuencia de una alimentación superior arraigada en la explotación de los recursos naturales. En este punto, cabe recordar que Argentina fue conocida como el "granero del mundo"; en los albores del siglo XX, el país se encontraba formando parte de un escenario económico mundial en el cual se posicionaba como productor de bienes primarios exportables a partir de las iniciativas de las elites dominantes. ${ }^{10}$ Ocupar este lugar - cimentado en lo que en adelante llamaremos modelo agroexportador - fue posible gracias al importante flujo de inmigrantes de ultramar que arribaron a estos territorios, dinámica también impulsada por los sectores sociales más encumbrados. Toda esta población se derramó por vastas regiones, poniendo en producción gran parte de la tierra hasta ese momento improductiva y generando un crecimiento demográfico exponencial. ${ }^{11} \mathrm{~A}$ su vez, ese ingreso masivo de población deseada habría generado consecuencias negativas: "un movimiento obrero que no era fácil de disciplinar, delincuencia, desorden, problemas sanitarios y habitacionales en las grandes ciudades". ${ }^{12}$

En relación a lo anterior, los aún larvados sectores medios de la sociedad - en gran parte formados por los hijos de los inmigrantes - fueron los gestores de dos fenómenos de gran importancia para la sociedad argentina: la llegada, luego de veinte años de lucha, de la Unión Cívica Radical al Gobierno de la Argentina y la Reforma Universitaria, hecho que tuvo como epicentro la Universidad de Córdoba y que generó cambios esenciales en los estudios superiores argentinos y latinoamericanos. ${ }^{13}$

8 La epidemia desconocida. La Nación, Buenos Aires, 6 jun. 1918.

9 Epidemia gripal. La Nación, Buenos Aires, 16 jun. 1918.

10 Para mayor información véase ROFMAN, Alejandro; ROMERO, Luis. Sistema socioeconómico y estructura regional en la Argentina. Buenos Aires: Amorrortu, 1997.

11 Para mayor información véase OTERO, Hernán. Estadística y Nación. Una historia conceptual del pensamiento censal de la Argentina moderna, 1869-1914. Buenos Aires: Prometeo Libros, 2006.

12 SURIANO Juan. La cuestión social en Argentina, 1870-1943. Buenos Aires: Editorial La Colmena, 2000. p. 1.

13 Para mayor información véase TÜNNERMANN, Carlos. Noventa años de la Reforma Universitaria de Córdoba (1918-2008). Buenos Aires: Consejo Latinoamericano de Ciencias Sociales, 2008. 
En el marco, entonces, de esta explosión demográfica, de cambios socio-políticos trascendentales, la pandemia que se producía en el otro lado del Océano Atlántico era un problema que poco importaba a un Estado argentino que tenía que hacer frente a otras enfermedades infectocontagiosas como la tuberculosis, la viruela, etc.

Pese a la escasa atención que recibió en estas latitudes, la gripe española terminó por arribar a las costas rioplantenses; llegó a la Argentina en el vapor Demerara que, zarpando de Europa, había hecho escala en Rio de Janeiro donde ya la enfermedad hacía estragos. De manera específica, las fuentes indican que el 22 de octubre se descubría el caso cero en Buenos Aires y, a partir de ese momento, el mal se desarrollaría en la ciudad extendiéndose luego hacia la mayor parte del territorio nacional entre los meses de octubre y diciembre de 1918.

De acuerdo a la información recogida en investigaciones previas, ${ }^{14}$ y según los testimonios de médicos de la época, para las provincias argentinas se puede estimar una mortalidad en valores absolutos de 1.969 personas que presentarían como causa de muerte la gripe. Empero, el boletín demográfico del Departamento Nacional de Higiene arroja información que nos permite inferir que muchos casos de gripe española fueron confundidos como dolencias de carácter broncopulmonar. ${ }^{15} \mathrm{~A}$ partir de identificar estos rasgos, hemos considerado necesario formular valores de sobremortalidad en los meses de la epidemia; es decir, se restaron los valores de los meses de octubre, noviembre y diciembre de 1918 a los mismos meses de los años 1917 y 1919. Este cálculo dio como resultado 1.960, por lo cual se podría suponer que fallecieron unos 3.929 sujetos como consecuencia de haber contraído gripe española. A esto debería añadirse lo sucedido en los territorios nacionales, ${ }^{16}$ que en ese momento no enviaron las estadísticas de mortalidad por gripe, hecho que determinó que esa información no fuera publicada por los Anales del Departamento Nacional de Higiene. En función de ello, entonces, estimamos la mortalidad de dicha zona a partir de su cercanía con alguna provincia, de acuerdo con similitudes de clima y características sanitarias de algunas de ellas; esto arrojó para 1918 un total de 317 muertes más. Así, nos aproximamos a un total de 4.256 muertes por gripe española para todo el territorio argentino.

En 1919, la puerta de ingreso de la enfermedad habría sido la región norte del país. Este azote tuvo la particularidad de ser manifiestamente más virulento que el del año previo, suscitando un impacto devastador en términos demográficos y a escala nacional. En efecto, la gripe habría generado un total 12.755 muertes de acuerdo a las estadísticas oficiales. Ahora bien, si repetimos el cálculo que hicimos para el brote anterior, la sobremortalidad de bronconeumonías sería de 3.836 casos, hecho que revela una mortalidad de 16.591

14 CARBONETTI, Adrián; RIVERO, María Dolores. Argentina en tiempos de pandemia: la gripe española de 1918-1919. Leer el pasado para comprender el presente. Córdoba: UNC Editorial, 2020.

15 Anales del Departamento Nacional de Higiene, 26, p. 323, 1920.

16 Esta denominación recibieron las tierras ubicadas fuera de los límites de las primitivas catorce provincias que integraban el país a principios del siglo XX. Se trataba de los territorios de Misiones, Chaco, Formosa, La Pampa, Neuquén, Río Negro, Chubut, Santa Cruz y Tierra del Fuego. 
personas. Si a esos datos agregamos el cálculo sobre los territorios nacionales obtenemos la cifra de 1.391 muertes por gripe, con lo cual la mortalidad por influenza para 1919 ascendería a 17.982. Podría decirse, entonces, que la mortalidad por la pandemia en la Argentina considerando ambas oleadas - habría sido de 22.238 individuos. ${ }^{17}$

El gráfico 1 posibilita apreciar el comportamiento de la enfermedad en las distintas regiones del país y en su totalidad.

\section{Gráfico 1 - Mortalidad por gripe española en Argentina, total y regiones en los brotes de 1918 y 1919}

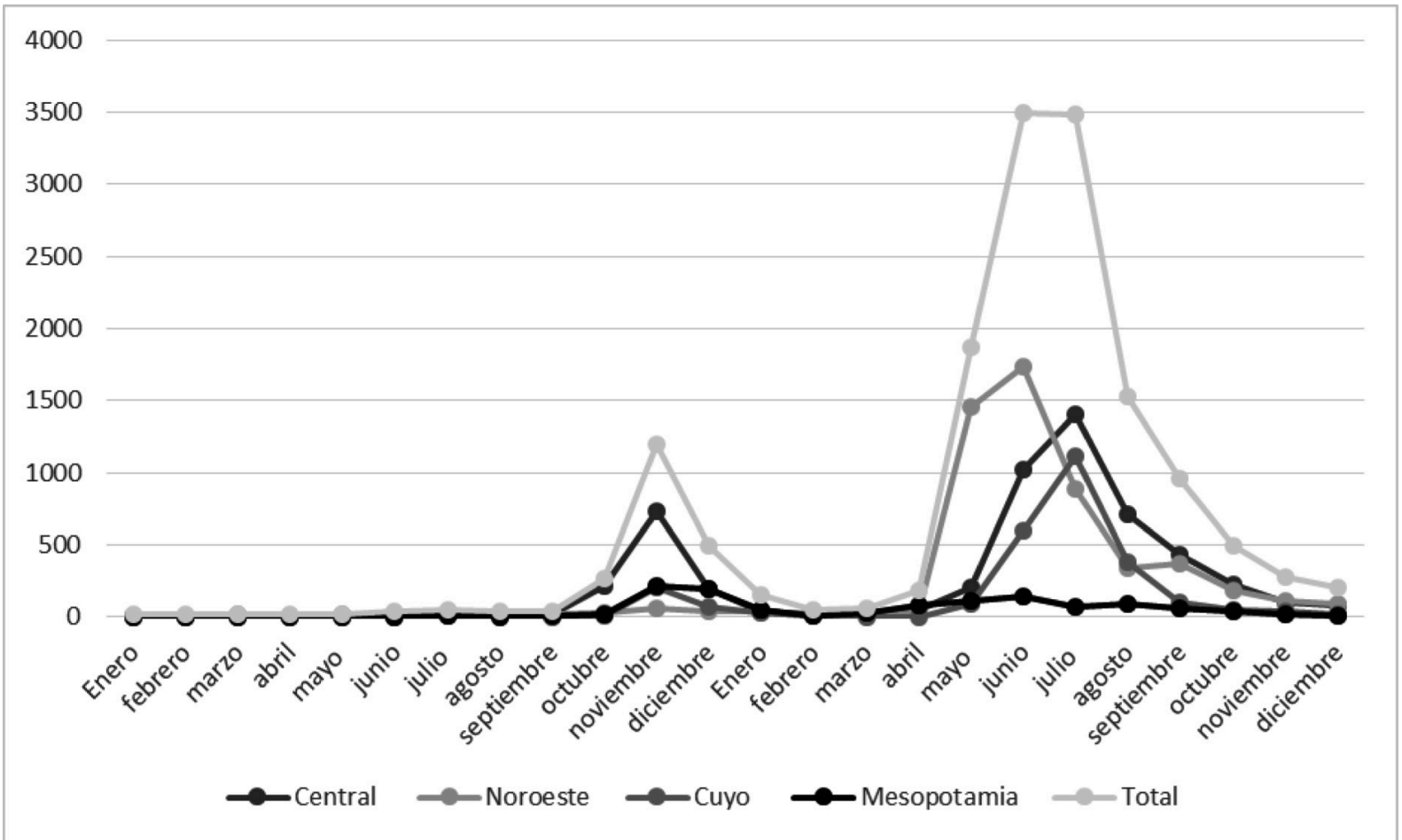

Fuente: elaboración propia sobre la base de datos de Anales del Departamento Nacional de Higiene, n. 26, 1920.

\section{Gripe española y lógicas económicas ${ }^{18}$}

Toda dolencia PANDÉmica o epidémica, de carácter infeccioso, suele traer consigo efectos devastadores para las variables económicas; ciertamente, algunos trabajos centrados en una perspectiva histórica han demostrado que el advenimiento de una enfermedad implicaba que se cerraran ciudades o regiones, que el comercio se interrumpiera, que muchos puestos fuesen abandonados porque los obreros caían enfermos y la población comenzaba a ceñirse a las medidas de aislamiento (en algunos casos de manera voluntaria, pero en la mayoría obligados por la autoridad médica). Esto mismo sucede con la economía en tiempos de

17 CARBONETTI; RIVERO, op. cit., 2020.

18 Agradecemos especialmente al Dr. Juan Mario Jorrat, director del Centro de Investigación del Ciclo Económico y Crecimiento, por proveernos de las fuentes necesarias para elaborar este apartado. 
pandemia de covid-19 y aconteció también, aunque en menor medida, durante los brotes de gripe española.

Esta dolencia se desarrolló en las postrimerías de la Primera Guerra Mundial, generando una alta mortalidad en los soldados del frente y en las sociedades de los países que estaban implicadas en el conflicto, para luego pasar a las naciones neutrales. En términos económicos, los países afectados por el brote mostraron caídas en su Producto Bruto Interno (en adelante, PBI). Sergio Correia, Stephan Luck y Emil Verner concluyen - luego de analizar los efectos de la gripe española sobre la población de los Estados Unidos - que la pandemia condujo a una caída aguda y persistente en la actividad económica. ${ }^{19}$

La economía argentina no parece haber escapado de esta tendencia durante los brotes pandémicos; los datos examinados permiten verificar que en los años 1918 y 1919 se habría producido una caída del PBI.

\section{Gráfico 2 - Comportamiento del PBI anualizado entre 1916 y 1921 en Argentina}

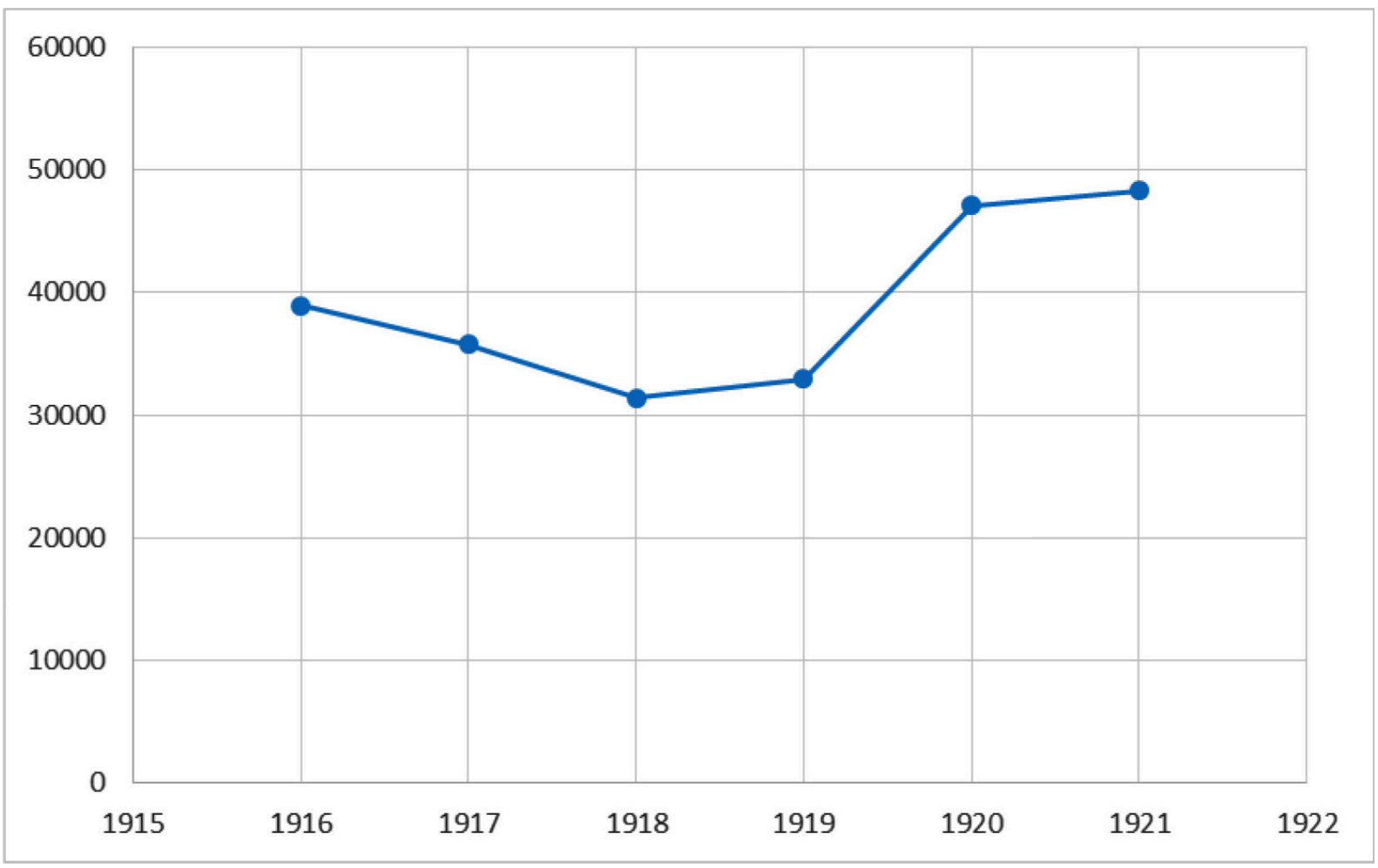

Fuente: elaboración propia sobre base de datos de JORRAT, Juan M. Centro de Investigación del Ciclo Económico y Crecimiento. San Miguel de Tucumán, Argentina, 2020.

Como se puede apreciar a partir del gráfico 2, durante los años 1918 y 1919 se produjo una caída del PBI que ya venía delineándose desde 1917, tendencia que culmina con un

19 CORREIA, Sergio, et al. Fight the Pandemic, Save the Economy: Lessons from the 1918 Flu. Federal Reserve Bank of New York - Liberty Street Economics, New York, 27 mar. 2020. Disponible en https:// libertystreeteconomics.newyorkfed.org/2020/03/fight-the-pandemic-save-the-economy-lessons-from-the1918-flu.html. 
crecimiento importante de este indicador a partir de 1920. Es posible que muchos factores hayan influido sobre el desarrollo de esta crisis; entre ellos, es dable remarcar posibles problemas en las cosechas, las frecuentes muestras de malestar obrero - cristalizadas en sucesivas y acaloradas protestas entre 1917 y 1919 -, como consecuencia del deterioro del salario real durante la guerra, signado por el aumento de precios. Otro aspecto a considerar es la gran cantidad de emigrantes que sobrepasó a la de inmigrantes, fenómeno al que no se asistía desde 1890. En esta tónica, y "a pesar de que el cambio de signo en la balanza migratoria hacía disminuir el número de personas dispuestas a trabajar, la desocupación aumentó hasta convertirse en un grave problema social". ${ }^{20}$

Ahora bien, también es preciso señalar - a propósito de esa marcada caída y de sus posibles causas - que el desarrollo de la pandemia en el país se dio en los últimos meses de 1918, por lo cual no podría asegurarse haya generado un mayor impacto sobre el PBI. A partir de esta consideración entendemos que cobra importancia realizar un análisis del comportamiento del PBI de Argentina ajustado por estacionalidad. Así, en el gráfico 3 podemos apreciar que el impacto de la gripe española sobre la economía argentina sería especialmente en el segundo trimestre de 1919, momento en el que se produjo la mayor declinación del PBI.

Gráfico 3 - Comportamiento del PBI por estacionalidad entre 1917 y 1920 en Argentina

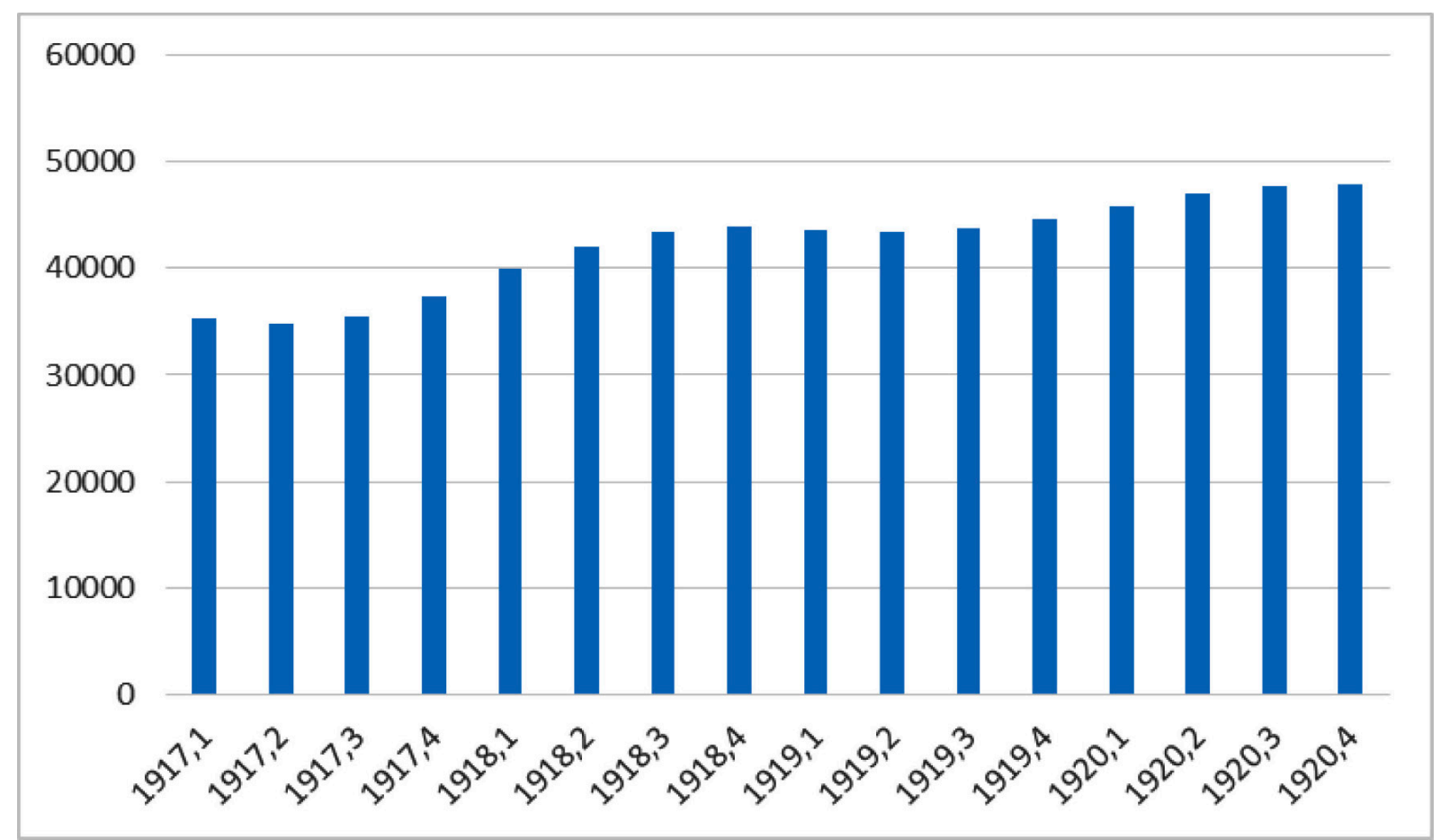

Fuente: elaboración propia sobre base de datos de JORRAT, op.cit.

20 GERCHUNOFF, Pablo; LLACH, Lucas. El ciclo de la ilusión y el desencanto. Un siglo de políticas económicas argentinas. Buenos Aires: EMECÉ, 2010. p. 73. 
De acuerdo con los señalamientos de Alejandro Diaz, ${ }^{21}$ para este momento de la historia económica argentina el PBI se componía en un $25,2 \%$ del sector rural, un $26,7 \%$ del sector industrial y un $48,1 \%$ por el sector servicios (éste incluía comercio, transporte, comunicaciones, etc.). Estas cifras estarían indicando, en línea con los planteos de Gerchunoff y Llach, que "la expansión industrial previa a 1914 no fue menor". ${ }^{22}$ Las manufacturas cuya producción creció más fuerte fueron las que dependían del tipo de desarrollo agroexportador de la época. Siguiendo a los autores, subrayamos que se conoce como "eslabonamiento" a la aparición o desarrollo de una cierta actividad económica cuando es el resultado del crecimiento de otra. Estos eslabonamientos pueden ir en dos direcciones: si se expande cierta actividad gracias a la abundante disponibilidad de un insumo se habla de "eslabonamiento hacia adelante". Cuando, al contrario, el progreso de una industria genera una demanda por algún insumo, y en consecuencia se instalan empresas para satisfacer esa demanda, el nexo se conoce como "eslabonamiento hacia atrás". Para Gerchunoff y Llach, por lo menos hasta la Primera Guerra Mundial, el surgimiento de la mayoría de las industrias argentinas puede entenderse en los términos del eslabonamiento hacia adelante. Así, hallamos la aparición de industrias de alimentos y bebidas, favorecidas por el bajo costo de las materias primas, mientras que las fábricas de cerveza (Bieckert y Quilmes entre ellas), los frigoríficos y los molinos azucareros también fueron consecuencia de la consagración de la Argentina a la producción agrícola y ganadera. ${ }^{23} \mathrm{La}$ importante industria vitivinícola de Mendoza es otro ejemplo en este rubro, junto con el procesamiento de cueros y los tejidos de lana.

Durante la guerra, este sector atravesó - aunque tímidamente aun - lo que la historiografía ha denominado "industrialización por sustitución de importaciones", pues el país dependió de sí mismo para procurarse las manufacturas en el contexto bélico reinante. Se trató de un cierre de la economía de carácter natural, en el que no hubo una decisión de política económica mediando. ${ }^{24}$

Va de suyo que estas actividades implicaban una importante cantidad de mano de obra, afincada fundamentalmente en las urbes. Una revisión comparativa entre el campo y estos espacios permite constatar que la gripe española sacudió en mayor medida a las poblaciones que habitaban las ciudades, donde el sector de servicios era preponderante. Por lo tanto, es dable suponer que el comercio y la producción, así como también los servicios estatales, estuviesen impedidos. Estas restricciones deben ser vislumbradas a partir de dos factores clave: por un lado, la generación y puesta en marcha de medidas que inhabilitaban el normal de desarrollo de esas actividades en vistas de cortar con la cadena de contagios. Por otro, las bajas que producía la gripe en la fuerza laboral.

21 DIAZ, Alejandro. Ensayos sobre la historia económica argentina. Buenos Aires: Amorrortu, 2000.

22 GERCHUNOFF; LLACH, op. cit., p. 37

23 Ibidem, p. 37-38.

24 Ibidem, p. 70. 


\section{La pandemia en 1918 y sus efectos en la actividad laboral}

Como observábamos pReViamente, la pandemia de gripe española se presentó en Argentina en dos oleadas: en la primavera de 1918 y en el otoño-invierno de 1919. El primero de estos asaltos irrumpió fuertemente en la ciudad de Buenos Aires y en menor medida en las provincias centrales, siendo casi nula su incidencia en el noroeste. A esta altura, conviene no soslayar el hecho de que la ciudad de Buenos Aires se constituyó como una suerte de faro para la Argentina, siendo el caso por antonomasia de temprana y dinámica concentración demográfica. Su superioridad se remonta a los años de independencia de la corona española, momento a partir del cual los antiguos dominios rioplatenses ingresaron en una contienda que no culminaría sino hasta fines del siglo XIX. "A lo largo de todos esos años, la ciudad de Buenos Aires logró ir consagrándose paulatinamente como la reina del Plata, en parte gracias a las rentas de su aduana, como también al arribo de capital, tecnología, inmigrantes y el contacto con culturas extranjeras". ${ }^{25}$ Finalmente, los extensos conflictos por la organización nacional terminaron con la federalización de Buenos Aires, lo que acabó por marcar un derrotero de predominio sobre el resto del país. ${ }^{26}$

Las estimaciones en torno a la densidad poblacional de la metrópoli señalan que para 1904 la Capital Federal contaba con 950.891 habitantes. ${ }^{27}$ Sin lugar a dudas, esta concentración demográfica arrastraría consigo un cuadro de salubridad sumamente complejo y problemático, susceptible de ser observado en los conventillos. Es que tal y como señala Armus, ${ }^{28}$ la gran aldea y sus recurrentes azotes epidémicos debían quedar atrás si se quería construir una ciudad y una nación modernas. Verosímilmente, esta cuestión fue abordada institucionalmente ya en el ocaso del siglo $\mathrm{XIX},{ }^{29}$ a partir de la creación de la Asistencia Pública, "repartición que coordinaría y centralizaría la acción del municipio en relación a las enfermedades de los pobres, tanto en los hospitales como en sus lugares de residencia". ${ }^{30}$ En línea con los planteos de Caride, entendemos "que las amenazas de las epidemias, en general, fueron la verdadera impulsora de los conceptos higienistas". ${ }^{31}$

Los sucesos epidemiológicos de mayor trascendencia que dejarían al descubierto la preocupación por la situación sanitaria de Buenos Aires serían los brotes de cólera y fiebre

25 RIVERO, María Dolores. Dinámicas publicitarias en materia de aparatología terapéutica y farmacología. Una aproximación a los mercados de Córdoba, Rosario y Buenos Aires (1912-1938). Tesis (Doctorado en Historia) - Facultad de Humanidades y Ciencias de la Educación, Universidad Nacional de La Plata, La Plata, 2019. p. 67.

26 RAPOPORT, Mario y SEOANE, María. Buenos Aires, historia de una ciudad: 1880-1955. Buenos Aires: Planeta, 2007.

27 Número diez veces mayor que el de la ciudad de Córdoba.

28 ARMUS, Diego. El descubrimiento de la enfermedad como problema social. In: LOBATO, Mirta (dir.), Nueva Historia Argentina. El progreso, la modernización y sus límites (1880-1916). Buenos Aires: Sudamericana, 2000. p. 507-551.

29 En 1883, por iniciativa de José María Ramos Mejía, fundador del Círculo Médico Argentino.

30 GUTMAN, Margarita; HARDOY, Jorge Enrique. Buenos Aires 1536 - 2006. Historia urbana del área metropolitana. Buenos Aires: MAPFRE, 1992. p. 103.

31 CARIDE, Horacio. Suburbio, Higiene y Utopía en el Buenos Aires de entre siglos. Crítica, v. 88, p. 1-45, 1998. p. 26. 
amarilla en 1870-871;32 episodios que, como es sabido, sacudieron la vida social e institucional de los porteños. A partir de entonces hubo una serie de transformaciones, fundamentalmente en la estructura física de la ciudad; la acción municipal operó sobre la infraestructura: se construyeron redes de agua corriente y cloacas, se rellenaron los antiguos arroyos, se adoquinaron las calles y también se controló la limpieza y salubridad de los inquilinatos del Barrio Sur próximos a la Plaza de Mayo. ${ }^{33}$

Sin embargo, aquellas mutaciones no serían suficientes para encarar y paliar un flagelo de la envergadura de la gripe española. La información que llegaba del exterior y la forma en cómo se desarrolló la enfermedad en esta ciudad forjaron la puesta en acción de medidas destinadas a frenar el curso de la infección que, naturalmente, afectaron el mundo del trabajo. José Tobías - en su tesis titulada "La epidemia de grippe 1918-19" - muestra un panorama sumamente esclarecedor acerca de los sectores que fueron afectados durante el brote de 1918,

en Buenos Aires observamos la rapidez de difusión en el personal de los bancos, de las grandes reparticiones públicas y privadas, en los cuartes, cuerpos de bomberos, depósitos de marinería, fábricas y colegios, etc., que fueron otros tantos focos que permitieron la fácil explosión de la enfermedad reinante en toda la ciudad. ${ }^{34}$

Según observaba Tobías, prácticamente todos los sectores del trabajo y la producción de Buenos Aires habían sido afectados por el desarrollo de la gripe española, especialmente, a partir de una alta morbilidad en los trabajadores. Ahora bien, el tesista también prestaba atención al hecho de que la enfermedad no sólo generaba baja de producción, sino también en una caída en la demanda: "Las grandes casas de comercio vieron faltar más de la tercera parte de los empleados, siendo más que suficientes los restantes para atender el escaso número de compradores. ${ }^{35}$

En ese mismo pasaje, galeno denunciaba que - como consecuencia de la gripe - la actividad había disminuido en todas partes; pero no sólo la producción, también el transporte sufría como consecuencia del desarrollo de la enfermedad: "Las empresas ferroviarias y de tranvías vieron reducir su personal a las dos terceras partes, hubo momentos en que se creyó que a la disminución del tráfico debía suceder el para absoluto por ausencia del personal". ${ }^{36}$ Por su parte, los servicios de correo y los telégrafos también se encontraban paralizados como derivación de la dama española. ${ }^{37}$

En suma, todos los sectores de la economía comenzaron a disminuir su ritmo a niveles muy por debajo de la normalidad; producción y servicios cayeron a un tercio de su actividad,

32 MALOSETTI COSTA, Laura. Buenos Aires 1871: imagen de la fiebre civilizada. In: ARMUS, Diego (comp.). Avatares de la medicalización en América Latina 1870-1970. Buenos Aires: Lugar editorial, 2005. p. 41-65. 33 RIVERO, op. cit., p. 68.

34 TOBÍAS, José. La epidemia de grippe de 1918-19, Tesis (Doctorado en Medicina) - Facultad de Medicina, Universidad de Buenos Aires, Buenos Aires, 1920. p. 22-23.

35 Ibidem, p. 15.

36 Ibidem, p. 15.

37 Ibidem, p. 13. 
mientras el personal sanitario no alcanzaba para poder atender a todos los pedidos de auxilio: "la labor profesional llegó a un máximo nunca alcanzado". ${ }^{38}$

Otro de los puntos destacados por el tesista remite a una arista en tanto problema social de la dolencia: eran más rudamente castigados los individuos que trabajan en locales en malas condiciones higiénicas, demostrando el azote una predilección particular por los aglomerados. ${ }^{39}$ Estos señalamientos deben ser considerados en un contexto particular:

desde fines del siglo XIX, en la Argentina, los sindicatos, los partidos políticos y el movimiento anarquista venían denunciando, entre otras cuestiones, las pésimas condiciones de higiene y de labor en las fábricas. Con diferentes matices discursivos y de protesta interpretaban que las enfermedades que contraían y los accidentes que sufrían los trabajadores en su puesto laboral constituían uno de los aspectos visibles de una relación basada en la explotación y que sólo apuntaba a aumentar los márgenes de la ganancia capitalista. ${ }^{40}$

Es decir, la gripe venía a sumarse a un escenario previamente configurado de condiciones laborales paupérrimas. A partir de allí, no resulta sorpresivo que muchos de los obreros cayeran en cama o murieran como consecuencia de la enfermedad. Claro que para el médico existía otra razón para las bajas en los talleres: que los individuos preferían recluirse en sus casas ya que "vio en las aglomeraciones el mejor medio utilizado por la epidemia para su difusión" ${ }^{41}$ En otras palabras, el galeno plateaba la puesta en marcha de una cuarentena "voluntaria" y aislamiento por parte de la población que se sumaban a las medidas que imponía el gobierno central. Esta últimas reflejaban escasa rigurosidad pese al escenario que transcurría:

las informaciones recogidas por este departamento hacen saber que la actual epidemia de grippe se ha extendido entre el personal obrero que trabaja en las fábricas y talleres de la Capital federal. En las principales fábricas, la proporción de inasistentes por razones de enfermedad excede de un $30 \%$. Hay establecimientos en los que la proporción indicada llega a $40 \%$ y $50 \% .{ }^{42}$

Sin embargo, el Departamento de Trabajo no veía con buenos ojos el cierre de locales debido a que esto implicaría un freno para la industria y los obreros dejarían de cobrar sus salarios. Por tanto, se proponía la denuncia de los propietarios de los talleres cuando la inasistencia llegara a más del $20 \%$ del personal, medida que los dueños no cumplieron debido a que ésta podría traer aparejado el cierre del local.

Para finalizar, cabe aclarar que el gobierno se mostró menos permisivo con otros sectores de la vida económica del país, como el de los espectáculos y los bares. En efecto, los primeros quedaban inhabilitados para abrir sus puertas, mientras los segundos debían adherir a un régimen horario específico. Al respecto, la revista porteña Caras y Caretas se

38 Ibidem, p. 16.

39 Ibidem, p. 14

40 RAMACCIOTTI, op. cit., 2011, p. 268.

41 TOBÍAS, op. cit., p. 17.

42 Expediente N. ${ }^{\circ} 6841$, Archivo Intermedio del Archivo General de la Nación, Archivos del Ministerio del Interior, 23 oct. 1918. 
hizo eco de la medida y mostraba a los dueños de teatros y cinematógrafos reunidos ante la preocupación.

Imagen 1 - Empresarios reunidos en el Teatro Nacional

El cierre de teatros y cinematógrafos

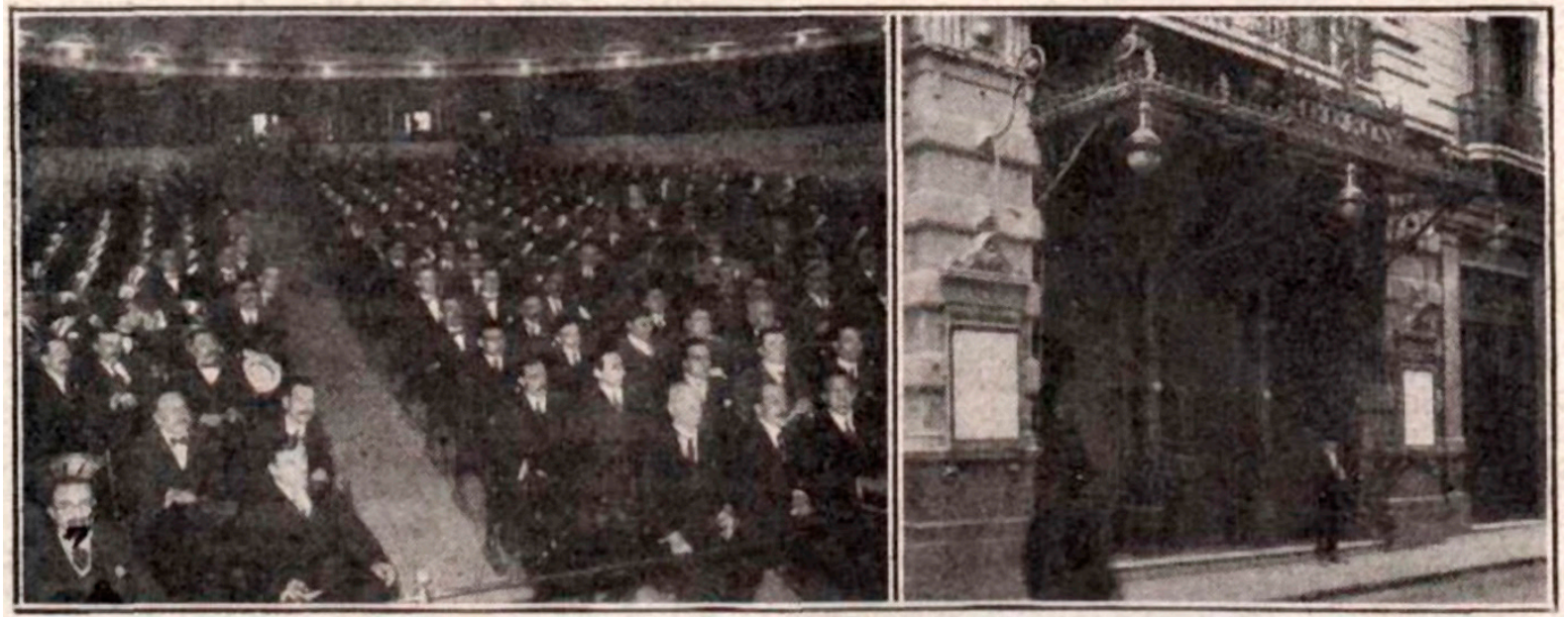

Fuente: Caras y Caretas. Año XXI, n. 1048. Buenos Aires, p. 48, 2 nov. 1918.

\section{Dinámicas laborales en 1919: cese de actividades y nuevos empleos}

COMO NO PODRÍA ser de otra manera, el brote de gripe de 1919 implicó alteraciones en el universo laboral como ya había sucedido durante la primavera del año previo. No obstante, como ya anticipáramos, en esta segunda oleada el virus arribó en los meses de otoño-invierno. El 27 de mayo el diario La Nación ya se hacía eco del suceso informando acerca de las primeras modificaciones que sufriría el mercado laboral: el Departamento Nacional de Higiene instaba a quienes estuvieran enfermos de gripe a quedarse en sus casas y no acudir a sus lugares de trabajo. ${ }^{43}$

En esta tónica prohibitiva, el diario La Prensa cronicaba que en Salta no estaba admitido que se llevaran a cabo espectáculos públicos y los comercios debían cerrar a las 22 hs, ${ }^{44}$ mientras se vedaba terminantemente el funcionamiento de cinematógrafos, teatros, bailes $^{45}$ y otras actividades. Un escenario similar se viviría en la provincia de Córdoba; allí - de acuerdo con el periódico consultado - el Consejo de Higiene no llevaría a cabo rápidamente la clausura de locales públicos, pues apelaba al "sentido común" de los ciudadanos. Ciertamente, se esperaba que los propios individuos tuvieran presentes los peligros que implicaba ubicarse en grandes aglomeraciones y, a partir de ello, las evitaría.

43 Medidas precaucionales. La Nación, Buenos Aires, 27 mayo 1919.

44 Salta. Estado Sanitario. La Prensa, Buenos Aires, 8 mayo 1919.

45 El cierre de los cafés, confiterías, cantinas, fondas, etc y de las iglesias. Nueva Época, Salta, 8 mayo 1919. 
Esta confianza se revirtió y, a partir de principios de junio, los bares, cafés y biógrafos de la ciudad cerrarían sus puertas al público a partir de las $21 \mathrm{hs}$. Dicha medida resulta llamativa al constatar que la nota del diario llevaba el subtítulo "su enorme desarrollo en la ciudad", en referencia a la gripe. Sin embargo, en otros pasajes del cuerpo del texto se hacía alusión al hecho de que este nuevo brote era sumamente benigno comparado con el del año anterior y con los estragos que estaba causando en las provincias del norte. Ciertamente, como señalan Carbonetti, Gómez y Torres en su estudio sobre el caso salteño, en aquellas latitudes la gripe produjo una crisis de mortalidad, situación sobre la que volveremos más adelante. ${ }^{46}$

Para el caso de la región de Cuyo, las autoridades de la provincia de San Juan fueron menos laxas y dispusieron el cierre total de escuelas, teatros y salas de espectáculos, sin posibilidades de apertura en determinadas franjas horarias. ${ }^{47}$

Va de suyo que todas estas directrices modificaron los ingresos de los dueños de los mencionados establecimientos aunque, en términos comparativos, eran mucho más abultados que, por ejemplo, los de los feriantes de Sumalao en Salta. Es que aquel evento - uno de los más antiguos del Valle de Lerma - también se suspendería como consecuencia del azote.

Durante el brote de 1919 hubo otras actividades que se vieron resentidas, fundamentalmente por la salud afectada de los trabajadores. Además de destacar la situación de los médicos contagiados, ${ }^{48}$ los periódicos del momento arrojaron luz acerca de esta problemática haciendo hincapié en los soldados. En apariencia, los cuarteles ubicados en las provincias de Córdoba, La Rioja y Salta fueron los más afectados por la gripe; no obstante, el caso de esta última provincia requiere un análisis aparte pues muestra un escenario devastador. El día 5 de mayo de 1919, el diario Nueva Época anunciaba que la gripe había atacado a la guarnición de Campo Belgrano "de una manera alarmante, produciendo casos fatales en el $10 \%$ de los atacados". ${ }^{49}$ Se trataba de un espacio habitado por 1300 hombres, que vivían - de acuerdo a lo expuesto por el periódico - en condiciones insalubres y no contaban con la presencia de un hospital de campaña. ${ }^{50} \mathrm{~A}$ partir de esta situación, se solicitaba que les otorgaran a estos jóvenes las licencias necesarias para retornar a sus hogares, pues quienes aún estaban sanos se encontraban hacinados con los enfermos.

Entendemos que esta situación no debe ser leía de manera aislada. Concretamente, porque en estudios previos se constató que la situación sanitaria de la provincia de Salta a comienzos del siglo XX - en términos generales - era verdaderamente alarmante. La ciudad y la provincia de Salta estaban insertas en un sistema epidemiológico de carácter

46 CARBONETTI, Adrián; GÓMEZ, Néstor Javier; TORRES, Víctor Eduardo Roque. La gripe española y crisis de mortalidad en Salta, Argentina, a principios del siglo XX. Historelo. Revista de Historia Regional y Local, v. 5, n. 10, p. 269-300, 2013.

47 Propagación de la gripe en el interior. La Nación, Buenos Aires, 21 jun. 1919.

48 La gripe. Nueva Época, Salta, 7 mayo 1919.

49 La gripe en Campo Belgrano. Nueva Época, Salta, 5 mayo 1919.

50 Al margen de la epidemia. Nueva Época, Salta, 10 mayo 1919. 
pretransicional, en el cual la mortalidad por enfermedades infectocontagiosas era estelar. Las instituciones allí eran escasas, hecho que imposibilitaba el cuidado de una población que atravesaba procesos dolientes a menudo, mientras los privilegios políticos, económicos y sociales daban ventajas en la atención a los sectores encumbrados de la sociedad. Podemos aseverar, entonces, que la gripe se presentó en una sociedad ya acechada por enfermedades endémicas - como el paludismo - y epidémicas, como también por niveles exorbitantes de mortalidad infantil. ${ }^{51}$

Otro de los sectores castigados por la gripe española fue el de los trabajadores del estado. Dentro de este grupo se hallaban, por ejemplo, los empleados de la casa de gobierno de Catamarca (entre los cuales había 20 enfermos) ${ }^{52}$ y los legisladores. Respecto a estos últimos, resulta interesante constatar que - a diferencia de lo que sucedía con los conscriptos un diario salteño se dirigía a ellos solicitándoles volvieran a sus puestos de trabajo. Aquella solitud se cimentaba en el hecho de que en la ciudad había, de acuerdo a la perspectiva del autor de la nota, elementos necesarios para ceñirse a todas las normas higiénicas: baños públicos, desinfecciones, ${ }^{53}$ entre otras.

Ahora bien, mientras muchos sectores laborales y profesionales se vieron sumamente limitados por la reaparición de la gripe en 1919, otros acrecentaron su actividad. En este sentido, es insoslayable el papel de las cuadrillas de peones que aumentaron su número y sus actividades para cumplir con tareas de saneamiento en múltiples puntos del país. A partir de ello, se catalizaron algunos pedidos y protestas, pues de acuerdo a las exigencias de vida (más la suba de precios de artículos) muchos decían contar con remuneraciones bajas. ${ }^{54}$

Una de las profesiones certificadas que también vio modificada su dinámica laboral fue la de los farmacéuticos. Si bien en algunos casos fueron cuestionados y llegaron informaciones negativas acerca de su accionar (como el de un farmacéutico salteño, de la zona de Orán, considerado un ignorante por el médico a partir de sus malos preparados y sus ventas aparentemente inescrupulosas), ${ }^{55}$ estas lecturas - teñidas por las históricas pugnas entre farmacéuticos y médicos diplomados ${ }^{56}$ - no deben opacar las particularidades de la labor este gremio. En efecto, el Consejo de Higiene de Salta dispuso aumentar el número de farmacéuticos de la Asistencia Pública debido a la demanda y que, durante la epidemia, todas las farmacias debían estar abiertas hasta las $22 \mathrm{hs}$, incluyendo los días domingo. ${ }^{57}$ Esta extensión de la jornada laboral se dio también en el caso del personal de policía ${ }^{58}$ y de ciertos trabajadores del estado que cumplían con sus actividades dentro de la casa Municipal de la

51 CARBONETTI; GÓMEZ; TORRES, op. cit.

52 La gripe en la República. Los principios, Córdoba, 15 mayo 1919.

53 La grippe y sus efectos políticos. Nueva Época, Salta, 22 mayo 1919.

54 Aumento de sueldos. Nueva Época, Salta, 10 jun. 1919.

55 Diversos informes sobre la situación pestosa en la provincia. Nueva Época, Salta, 6 jun. 1919.

56 Para mayor información, véase GONZÁLEZ LEANDRI, Ricardo. Autonomía y subordinación: los farmacéuticos diplomados y la constitución de un campo médico en Buenos Aires (1852-1880). Llull: Revista de la Sociedad Española de Historia de las Ciencias y de las Técnicas, v. 21, n. 40, p. 63-88, 1998.

57 El servicio de farmacias. Nueva Época, Salta, 8 mayo 1919.

58 Policía. Servicio permanente. Nueva Época, Salta, 3 jun. 1919. 
ciudad de Salta receptando denuncias en torno a la gripe y pedidos de ayuda asistencial de los sectores más carenciados de la sociedad norteña. ${ }^{59}$

Finalmente, para las hermanas - enfermeras este sobresalto epidémico no sólo implicó trabajar más horas, sino también movilizarse hacia múltiples parajes del país para asistir a los enfermos. Esto se observa, por ejemplo, en el traslado de enfermeras franciscanas hacia Salta para atender a los reclutas. ${ }^{60}$ Retomando otros abordajes historiográficos acerca de la distribución de ocupaciones en salud en el territorio argentino, es dable suponer que fuese necesario que arribaran a Salta especialistas de otras regiones. Verosímilmente, el censo de 1914 arroja un total de sólo 35 enfermeras para la aquella provincia, junto con solo 27 médicos. ${ }^{61}$ Tal vez, estos datos estadísticos puedan ayudar a entender las observaciones del diario Nueva Época sobre la situación de San Antonio de los Cobres. En dicho enclave, capital de la gobernación de los Andes y distante de 30 leguas de la estación más próxima de ferrocarril, toda la población se encontraba infectada. No había galenos ni medicamentos; los enfermos estaban abandonados a la mano de Dios, según el redactor. El único consuelo con el que contaban los pobladores eran las hechiceras de la comarca, si es que éstas no estaban también contagiadas de gripe. ${ }^{62}$ Seguidamente, la nota hacía referencia a estas prácticas en un tono despectivo, asociándolas a la barbarie. Si bien escapa a nuestras actuales inquietudes ahondar en asuntos vinculados a las prácticas curanderiles o mágicas, resulta importante destacar que este discurso estaba sumamente imbricado a otro, de igual o mayor resonancia, proveniente de gran parte de la tribuna médica. ${ }^{63}$

\section{Consideraciones finales}

EL EVENTO EPIDEMIOLÓGICO al que asistimos en los tiempos que corren nos interpela en tanto sujetos sociales, pero fundamentalmente como investigadores del campo de la salud y la enfermedad. Es que estamos en presencia de lo que podría ser considerada - tal vez por futuras generaciones de historiadores - la pandemia más virulenta del siglo XXI, al menos en términos de morbilidad. A partir de este suceso es que consideramos oportuno desandar los caminos de otro episodio clave en la historia mundial del siglo pasado: la gripe española. Nuestro estudio ha tenido por objeto arrojar luz acerca del impacto de este mal sobre la economía y las condiciones de trabajo en Argentina a comienzos del siglo XX. Hemos mostrado cómo el PBI de aquellos años se vio alterado, aunque considerando otros factores

59 Primeros auxilios. Nueva Época, Salta, 21 mayo 1919.

60 La situación de los cuarteles. La prensa, Buenos Aires, 13 mayo 1919.

61 RODRÍGUEZ, María Laura; CARBONETTI, Adrián; RIVERO, María DOLORES; FANTÍN, María A. Ocupaciones de la salud en el territorio argentino: perspectivas a partir de los censos nacionales de 1869, 1895 y 1914. Población y Sociedad, v. 25, n. 1, p. 75-101, 2018. p. 86.

62 Un pueblo en cama. Nueva Época, Salta, 17 mayo 1919.

63 Para mayor información véase RIVERO, María Dolores; CARBONETTI, Adrián; RODRÍGUEZ, María Laura. Alternativas al saber diplomado en la escena pública: una aproximación al curanderismo a partir de la prensa escrita de las ciudades de Córdoba y de Buenos Aires, Argentina en la década de 1920. Historia y sociedad, n. 33, p. 19-43, 2017. 
importantes que podrían haber tenido injerencia en la economía nacional y en la disminución de ese indicador: vicisitudes con las cosechas, protestas obreras, etc.

De igual modo, ingresamos en el estudio de las lógicas laborales que se suscitaron durante el brote de 1918, poniendo especial énfasis en la ciudad de Buenos Aires, pues se trató de uno de los enclaves más devastados por la dolencia. Como señalásemos, múltiples actividades se vieron imposibilitadas, tanto por las reglamentaciones prohibitivas como por las bajas a partir de los trabajadores que cayeron enfermos o decidieron aislarse en sus domicilios. En este sentido, vimos resentidos los servicios de transporte, telégrafos, correo; también las actividades recreativas que implicaran grandes aglomeraciones, como bares, restaurantes, confiterías y teatros.

Menos riguroso fue el gobierno con el asunto de la producción que involucraba mano de obra obrera. De acuerdo a lo constatado en las fuentes, los dueños de talleres solo debían denunciar situaciones extremas, cuando más del $20 \%$ de su plantel se viese comprometido por razones de salud.

Para el análisis de las implicancias laborales del brote de gripe de 1919 nos trasladamos al estudio de otras regiones del país, prestando especial atención al caso de una provincia del norte argentino (Salta), región más golpeada en esta segunda oleada. Como es posible observar en los documentos, este nuevo azote presentó la particularidad de inhibir, posibilitar e incluso ampliar una serie de labores. Hemos visto cómo en diferentes puntos del país se repitieron algunas de las normativas adoptadas el año anterior, aunque con algunas modificaciones y tendientes a una mayor flexibilización: en Córdoba, por ejemplo, se optó por el cierre de bares, cafés y biógrafos recién a partir de las 21 hs. Rescatamos, además, la indefensión y puesta en jaque de algunos empleos en particular, como el de los soldados, los médicos, de quienes trabajaban en los diarios, en reparticiones públicas, etc.

Sin embargo, también logramos verificar que la actividad de farmacéuticos, policías, peones de cuadrilla, hermanas - enfermeras y de personas implicabas en labores asistenciales crecieron exponencialmente.

En suma, este trabajo deja al descubierto cómo la aparición de la gripe española sacudió las estructuras económicas y productivas de diferentes regiones del país, generando lógicas laborales particulares.

Recebido em: 19/05/2020

Aprovado em: 12/08/2020 